\title{
Lo injusto de lo justo en salud
}

\author{
Carlos Tena-Tamayo* \\ Dirección General, Hospital Regional de Alta Especialidad del Bajío, León, Gto., México
}

Uno de los grandes retos del Sistema Nacional de Salud Mexicano es otorgar a todos los habitantes del país, sin importar su estatus económico, social o laboral, los servicios de atención médica que requieren, con oportunidad, calidad y sin costo al momento de la atención.

El derecho a la salud no existe como tal, ya que no es posible garantizar la salud, pues implicaría garantizar la propia vida, no obstante, sí existe la obligación del Estado de proteger la salud de los ciudadanos, y una de las formas de hacerlo es otorgando atención médica. Este mandato constitucional aún está lejos de cumplirse, la principal razón es de orden económico para poder contratar al personal de salud que se requiere, construir las clínicas y hospitales que se necesitan y comprar los medicamentos e insumos para tratar a todos los enfermos.

Las instituciones de la Seguridad Social están obligadas a otorgar la atención médica a sus derechohabientes, pues ellos, con sus cuotas, contribuyen a su pago de manera adelantada, pero la capacidad de respuesta de las instituciones aún no es la idónea, de tal forma que con frecuencia los pacientes deben esperar mucho tiempo para poder ser atendidos, o no siempre reciben sus medicamentos de manera completa. A veces esto propicia que la enfermedad progrese, pudiendo ocasionar mayor deterioro en la salud del enfermo.

Las personas que no tienen Seguridad Social, independientemente de su nivel socioeconómico, se pueden afiliar al Seguro Popular para recibir atención médica, pero en este, a diferencia de en la Seguridad Social, la gratuidad de la atención es solo para enfermos con ciertas patologías. Por medio del Seguro Médico Siglo XXI se financia la atención de niños menores de cinco años y mediante el programa de Protección contra Gastos Catastróficos se cubren algunas enfermedades en adultos, aunque varias son solo para ciertos grupos de edad. Este sistema ha sido de gran apoyo para millones de personas, sobre todo para los más necesitados, sin embargo, se requiere mayor financiamiento para cubrir sin costo la atención integral de todas las enfermedades.

En la actualidad es necesario que el paciente, de acuerdo con su nivel socioeconómico, pague una cuota de recuperación, establecida según un tabulador autorizado por la Secretaría de Hacienda y Crédito Público. La mayoría cubre el 10\% (nivel 1) del costo de la atención, pero en muchos casos debe pagar el precio completo de algunos medicamentos e insumos (prótesis valvulares de corazón, material de osteosíntesis, stents carotídeos o cerebrales, etc.) no incluidos en la cobertura que otorga el Seguro Popular.

Uno de los propósitos del actual Gobierno Federal es proporcionar atención médica y medicamentos gratuitos a toda la población que lo requiera. De alcanzarse, sería un gran avance en la justicia social, pues la atención médica dejaría de verse como una prestación laboral y se asumiría como un verdadero derecho constitucional.

\section{Correspondencia:}

${ }^{*}$ Carlos Tena-Tamayo

E-mail: carlostenat@gmail.com
Date of reception: 26-07-2019

Date of acceptance: 12-08-2019

DOI: $10.24875 /$ HMCM.19000219 
El reto sigue siendo identificar la fuente de financiamiento para que esto pueda ocurrir.

La inversión que se requiere en salud es mayúscula. Según datos de 2017, México solo invierte el 5.8\% de su producto interior bruto en salud, mientras que el promedio de los países de la Organización para la Cooperación y el Desarrollo Económico (OCDE) es del $9 \%$, esto significa que el gasto sanitario que realiza México es de 1.08 dólares por habitante, comparado con 4.003 dólares en el conjunto de la OCDE. Por lo tanto, los mexicanos deben gastar hasta el $41 \%$ de sus ingresos para atender su salud, cuando el promedio de los países de la OCDE es del $20 \%$.

Ante la falta de respuesta efectiva del Sistema Público de Salud, muchas personas enfrentan graves problemas cuando requieren de atención médica y no la reciben con oportunidad, ya sea por falta de acceso, debido a la saturación de los servicios, o porque les representa un costo elevado, que en caso de poderlo pagar, les generaría una catástrofe financiera familiar, y si no lo pueden hacer, tendrían que aceptar la evolución natural de la enfermedad con sus consecuencias.

Ante la desesperación, los pacientes buscan apoyos. Con frecuencia acuden con "gente pudiente o con influencias» para que los recomiende en el hospital en donde son atendidos. Es habitual que un político, amigo, compañero o familiar llame a un directivo del hospital para pedirle como favor que se adelante la cita a un familiar o conocido, o que se le otorgue de manera gratuita un medicamento o un insumo, o que no se le cobre la cuota de recuperación estipulada por la atención.

El directivo, como funcionario público, solo puede hacer lo que la ley le permite, por lo que aunque quisiera, no puede condonar el pago de una atención. El no cobro se da cuando se identifica en el paciente estado de indigencia, pobreza extrema o si es víctima de un delito, y en estos casos no se requiere ninguna recomendación, así está normado. Lo que sí se hace con frecuencia, es adelantar la cita para "un recomendado", siempre y cuando eso no perjudique a otro paciente. Claro que es justo atender de manera oportuna a un paciente, pero es injusto que no se dé esa oportunidad a todos, es decir, a los que no tienen «influencias».

En fechas recientes ha permeado la idea de que el sistema público de salud ya está en posibilidad de otorgar todos los medicamentos gratuitos a la población sin Seguridad Social, por lo tanto, los enfermos lo exigen, pero no siempre se puede cumplir con su expectativa. Por tal motivo, algunos pacientes han estado contratando abogados para que interpongan ante un juez una demanda para exigir su derecho a la atención médica integral. Este, argumenta el «derecho que se tiene a contar con un sistema de protección de la salud que brinde a las personas oportunidades iguales para disfrutar del más alto nivel posible de salud", por lo que ordena de manera inmediata al director del hospital demandado que entregue el medicamento y la atención médica que necesita el paciente, sin costo, aunque no exista financiamiento explícito para ello.

Los medicamentos que el juez obliga que se entreguen por lo general son de precio muy elevado, y al tenerlos que comprar el hospital por orden judicial, se disminuye la posibilidad de adquirir otros medicamentos para quienes sí cuentan con el apoyo de algún programa. Claro que es justo que todo paciente tenga sin costo sus medicamentos, pero es injusto que solo se les otorgue a quienes pudieron contratar a un abogado para obtener una orden judicial.

Tan injusto es que no tenga toda la población acceso a los mismos servicios de atención médica como que estos no se den con oportunidad y calidad, pero también lo es que solo se otorguen por la influencia de alguien o por la orden de un juez. Es injusto para todos aquellos que tienen que esperar o deben pagar porque no tuvieron ese apoyo.

En conclusión, lo injusto de lo justo en salud se da en el momento en que no se cuenta con un Sistema Nacional de Salud que cubra de manera equitativa todas las necesidades de atención médica de la población. Sabemos que se está trabajando para lograrlo, pero mientras sucede, se debiera considerar evitar mayores injusticias, sobre todo las promovidas por algunos abogados y ordenadas por jueces que, en su afán de ser justos, generan otras injusticias. 